\title{
Aeronautics and COVID-19: a Reciprocal Cause-and-Effect Phenomenon
}

\author{
Tessaleno Devezas ${ }^{1, *}$
}

How to cite

Devezas T iD https://orcid.org/0000-0002-7993-4919

Devezas T (2020) Aeronautics and COVID-19: a Reciprocal Cause-and-Effect Phenomenon. J Aerosp Technol Manag, 12: e3420. https://doi.org/10.5028/jatm.v12.1183

On February 26th, 2020, Brazil's Health Ministry confirmed the first Brazilian case of COVID-19, in São Paulo: a 61-year-old businessman who was in Lombardy, northern Italy. A second case was reported few days later of another person also returning from Italy. In Portugal, the first two cases were announced on March 2nd, 2020, a 60-year-old physician who returned from holidays in Lombardy, and a 33-year-old businessman returning from Spain.

What do these early cases of infected people in both countries have in common? What they have in common is the easy and fast movement of people through the air between continents. The virus SARS-Cov-2, the cause of COVID-19, was first confirmed to have spread to Italy on January 31st, 2020, when two Chinese tourists in Rome tested positive for the virus. One week later an Italian man returned from Wuhan and was confirmed as the third case. Soon after, on February 21 st, a cluster of 16 confirmed cases was detected in Lombardy. Chinese authorities tell us that the infection started to spread by the end of December from a wet market in Wuhan, in the Province of Hubei, China. It is important to observe the dates: from end of December to end of February, just two months! On March 12th, when the World Health Organization (WHO) declared the COVID-19 as a pandemic, we had already more than 10,000 cases confirmed all over the world and over 300 deaths to mourn. Presently, by the end of the seventh month after the record of the first cases in China, the numbers are frightening and astonishing: about 16 million infected and over 650,000 deaths, and still increasing.

In a recent opinion article of mine (Devezas, 2020a), entitled "The struggle SARS-CoV-2 vs. Homo sapiens - why the earth stood still, and how will it keep moving on?", to be published in a forthcoming issue of Technological Forecasting \& Social Change, I address the two most asked questions of our days: Why the surprise? And what comes next?

Regarding the former, I observed that the surprise lies not in the emergence of the pandemics itself, but in its profound and breathtaking effect on the global socioeconomic system, in the very short period of some few months. Such radical effect that has disturbed intensely the global economy may be attributed to two different agents: too much connectivity in our globalized world (mass movement of people in vehicles: cars, trains, busses, ships, and airplanes) and the very peculiar new properties of the SARS-CoV-2, being of note its longer time to present the first symptoms (ca. 1 to 2 weeks, when compared to the previous 3 or 4 days of similar virus like SARS and MERS). The simultaneous action of these two agents was catastrophic in the sense that it has revealed the fragility of our institutions and led to rapidly cascading effects on governmental and financial systems, which were prone to blow.

The focus of the present analysis is not to address in deep the above-mentioned questions, but instead the role of aeronautical transportation in the unfolding of the pandemics, and the expectations for the sector in the incoming years.

The title of this essay translates well my intention with these lines: to point out the interesting case of an interwoven cause-andeffect phenomenon that we see in aviation. If, on the one hand, aeronautical transportation may be blamed as one of the culprits for the rapid spread of the disease, it was also on the other hand one of the sectors of human activities hardest hit by the pandemics, annihilating thousands of jobs worldwide and threatening many airlines with bankruptcy.

1.Atlântica School of Management Sciences, Health, IT \& Engineering - Center for Aerospace Science and Technologies - Lisbon - Portugal.

*Correspondence author: tessalen@ubi.pt

Received: Jul. 26, 2020 | Accepted: Ago, 01, 2020 
In another paper of mine to be published in Technological Forecasting \& Social Change in the near future (Devezas, 2020b), I brought to attention the case of a possible "Jevons' paradox" or "rebound effect" in aviation. In a series of graphs, I demonstrated that, as flying by plane has become cheaper ("democratization of flying"), safer, and more efficient, the number of people transported by planes has increased by a factor of 10. Figure 1 presents this increase since 1975, using data from the International Air Transport Association (IATA) and the World Bank.

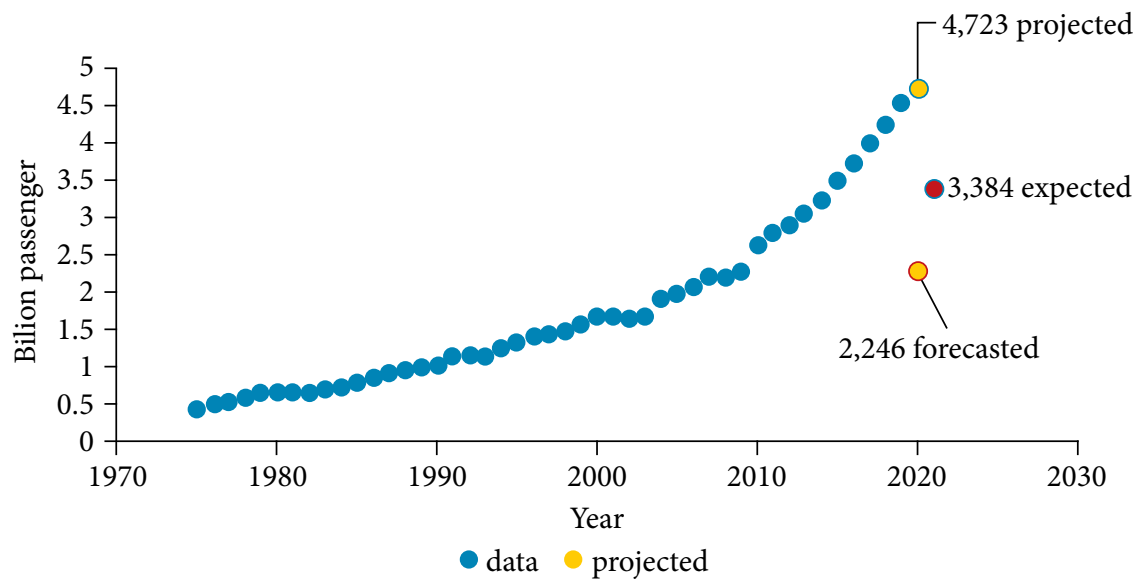

Figure 1. Yearly number of passengers carried globally according to the World Bank and IATA. The upper orange dot indicates the projected number pre-Covid-19, and the red dot exhibits the expected number for 2021, according to a relatively optimistic scenario. The lower orange dot indicates a probable (but optimistic) projection for 2020.

The upper orange dot for 2020 indicates the projected numbers of passengers, a forecast based on a supposed growth of at least $4 \%$. But now, considering that we are still in the first week of August and the pandemics is still spreading in many countries, and looking at the modest recovery of the sector after the relaxation of security measures all over the world, the relatively optimistic forecast is that this figure will reach the maximum of about 2.24 billion mark - in other words a fall of ca. 53\%! Important to observe that the yearly number refers to booked flights, and do not reflect the number of people flying. For instance, a person that flies once a week, every week, will count as 52 booked flights (passenger) in that year. A passenger flying on both the international and domestic stages of the same flight should be counted as both a domestic and an international passenger, then as 2 booked flights.

I am presently working in the construction of possible future scenarios for the aeronautical sector, but this is proving to be a very difficult task at the moment we are going through, such as looking for a black cat in a dark room wearing sunglasses. At global level, the pandemics is still spreading, and in many countries that did already overcome it, there is talk of new outbreaks and a second wave.

For the time being, the best solution is to follow the usual way of construction of at least three scenarios, which I will call here the good, the bad, and the ugly.

The first one, the good, is too much optimistic, believing in a kind of rebound or full recovery to precrisis level of demand, which I believe a little bit unrealistic. The third one, the ugly, is the most pessimist, believing that we will enter a long period of depression, similar to that of the 1930s, as has been anticipated by some economists, and further exacerbated by the growing geopolitical tensions between USA (with some allies) and Russia-China-Iran. I do not sincerely believe in such a negative scenario; we now have very different and more efficient economic measures than at that time.

So, let's speculate a little bit about the middle path. This is the path of what has been called the "new normal", and I coined it bad because it carries within it traces of the negative impact of the economic shock, but on the other hand it is also a little optimistic with regard to the necessary reorganization of institutions and a renewed people's attitude towards their social behavior.

I will try to resume bellow as a series of points, the main probable characteristics of this new normal:

- My research shows that world recovery of passenger demand to pre-COVID-19 levels may be estimated to take between 2 (recovery by late 2022) to 6 years (recovery in 2026).

- Within this scenario, we can expect that demand for 2021 will be within about $75 \%$ of the demand in 2019 (red dot in Fig. 1). 
- It is to expect, at the level of the "new normal", that health concerns may dampen consumer demand, while business travelers take to use more remote working, driven by cost reduction as well as having become accustomed to remote business practices during the pandemics.

- It is expected that the recovery may lead to a period of competition among airliners, being to expect then an increase in average ticket prices, driven by increased costs due to measures taken to prevent further spread of diseases, such as onboard distancing.

- This scenario contemplates the fact that airliners may accelerate the retirement of older widebody aircraft which are relatively expensive to operate and do not fit well with their long-term fleet strategy, while delaying retirement for narrow body aircraft by some years.

For now, it is very difficult to add more points to these few and most likely trends. Undoubtedly, an inevitable consequence of this crisis will be a reevaluation of fleets by all airliners. As I have shown recently (Devezas, 2020b), precrisis demand growth was leaded by narrow body aircraft. Thus, it is to expect that this trend will prevail for the next years, with widebody aircraft becoming increasingly obsolete.

\section{REFERENCES}

Devezas, T. (2020a in press) From my perspective: The struggle SARS-CoV-2 vs. Homo sapiens - why the Earth stood still, and how will it keep moving on? Technol Forecast Soc Change.

Devezas, T. (2020b in press) Trends in aviation: Rebound effect and the struggle composites vs aluminum. Technol Forecast Soc Change. 